\title{
Chromosomal Q-Heterochromatin and Sex in Human Population
}

\author{
Ibraimov A. I. ${ }^{1,2}$ \\ ${ }^{1}$ Institute of Balneology and Physiotherapy, Bishkek, Kyrgyz Republic \\ ${ }^{2}$ Kazakh National Medical University after name S. D. Asfendyarov, Almaty, Kazakhstan \\ Correspondence: Ibraimov A. I., Laboratory of Human Genetics, National Center of Cardiology and Internal \\ Medicine, Bishkek, Kyrgyzstan. E-mail: ibraimov_abyt@mail.ru
}

Received: January 27, 2014 Accepted: March 7, 2014 Online Published: March 21, 2014

doi:10.5539/jmbr.v4n1p10 URL: http://dx.doi.org/10.5539/jmbr.v4n1p10

\begin{abstract}
Individuals in the population differ from each other on the number, size, location and intensity of fluorescence of Q-heterochromatin regions (Q-HRs) of chromosomes. It is known that there is Y chromosome in a karyotype of males, which contains the largest block of Q-heterochromatin in human genome, and for this reason it is taken for granted that in total there is on average twice more Q-HRs in the genome of male than of female. However, the question on the existence of differences between the sexes on the quantitative content of chromosomal Q-HRs in the population still remains open. The fact is that the $\mathrm{Y}$ chromosome differs in its broad interindividual and interpopulation variability on the size of Q-heterochromatin material. A comparative analysis of the amount of chromosomal Q-HRs in the genome of male and female of different racial, ethnic and age groups showed that sex differences at the population level is much more complicated than heretofore assumed.
\end{abstract}

Keywords: chromosomal Q-heterochromatin, human Y chromosome, Q-heterochromatin polymorphism, Q-heterochromatin dose compensation, Q-heterochromatin selection

\section{Introduction}

A fundamental feature of chromosomes of higher eukaryotes, including man, is the presence of two evolutionary consolidated types of genetic material: euchromatin and heterochromatin. Euchromatin - the conservative portion of the genome - contains transcribed structural genes, while heterochromatin - the variable portion of the genome - predominantly consists of nontranscribed repeated DNA sequences (John, 1988; Verma, 1988).

To-date, two types of heterochromatin are known: C- and Q-heterochromatin. There are several significant differences between them, including the fact that $\mathrm{C}$-heterochromatin is encountered in chromosomes of all higher eukaryotes, while Q-heterochromatin is only present in man, the chimpanzee and gorilla. In man C-heterochromatin is present in all his chromosomes, varying mainly in size, while Q-heterochromatin can only be detected on seven autosomes and the Y-chromosome (Paris Conference, 1971, 1975).

Individuals in a population differ from each other on the number, location, size and intensity of staining (fluorescence) of chromosomal Q-heterochromatin regions (Q-HRs). It has been shown that certain human populations differ significantly as concerns this feature (Geraedts \& Pearson, 1974; Müller et al., 1975; Buckton et al., 1976; Lubs et al., 1977; Yamada \& Hasegawa, 1978; Al-Nassar, 1981; Ibraimov \& Mirrakhimov, 1982a, 1982b, 1982c; Ibraimov et al., 1982, 1986, 1990, 1991, 2000, 2013; Stanyon et al., 1988; Kalz et al., 2005; Decsey et al., 2006).

It is known that there is $\mathrm{Y}$ chromosome in a karyotype of males, which contains the largest block of Qheterochromatin in human genome, and for this reason it is taken for granted that in total there is on average twice more Q-HRs in the genome of male than of female (Paris Conference, 1971, 1975). However, the question on the existence of differences between the sexes on the quantitative content of chromosomal Q-HRs on autosomes in the population still remains open. The fact is that there is a link between the size of Q-heterochromatin on Y chromosome and the amount of Q-HRs on autosomes (Ibraimov et al., 2000). Moreover, the Y chromosome differs in its interindividual and interpopulation variability on the size of Q-heterochromatin material (Paris Conference, 1971, 1975; Verma, 1988). A comparative analysis of the amount of chromosomal Q-HRs on autosomes in the genome of male and female showed that sex differences at the population level is much more complicated than heretofore assumed. This fact is very important for understanding the possible biological role of the broad quantitative variability of human chromosomal Q-HRs. 


\section{Materials and Methods}

\subsection{Sample Characteristics}

Using identical methods we studied neonates, as well as students from Kazakh National Medical University in Almaty. The group of elderly subjects (aged 60 years and over) consisted of individuals living in the Old People's Homes of Almaty.

\subsection{Cytogenetic Methods}

Chromosomal preparations were made using short-term cultures of peripheral blood lymphocytes, with the exception of newborn infants where umbilical blood was used. The cell cultures were processed according to slightly modified (Ibraimov, 1983a) conventional methods (Hungerford, 1965). The dye used was quinacrine mustard. All the chromosomal preparations were analyzed by one and the same cytogeneticist (A.I.I.) to investigate chromosomal Q-HR variability. Calculation and registration of chromosomal Q-HRs was performed using the criteria and methods described in detail elsewhere (Ibraimov et al., 1982, 1990).

\subsection{Quantitative Characteristics of Q-HR Variability and Methods Used for Comparisons}

Chromosomal Q-HR variability in populations is usually described in the form of five main quantitative characteristics:

1) The distribution of the number of Q-HRs in a population, i.e., distribution of individuals having different numbers of Q-HRs in the karyotype regardless of their location on seven Q-polymorphic autosomes, which also reflected the range of Q-HRs variability in the population genome;

2) The derivative of this distribution, an important population characteristic, is the mean number of Q-HRs per individual;

3) The frequency of Q-HRs on seven Q-polymorphic autosomes (3, 4, 13-15, 21 and 22) in the population. Despite the fact that in human autosomes there are twelve loci in which Q-HRs can be detected ( 3 cen, 4 cen, 13 p11, 13 p13, 14 p11, 14 p13, 15 p11, 15 p13, 21 p11, 21 p13, 22 p11, 22 p13), individuals with 24 Q-HRs in their genome could exist, but such cases have not as yet been reported. In individuals of a population the number of Q-HRs on the autosomes usually ranges from zero to ten (Yamada \& Hasegawa, 1978; Al-Nassar et al., 1981; Ibraimov \& Mirrakhimov, 1985; Ibraimov, 2010).

4) The distribution of Q-HRs on autosomes according to their size and intensity of fluorescence (type of Q-variants), estimated as described by Paris Conference (1971, 1975).

5) The size of the $Y$ chromosome, being (a) large ( $Y \geq F)$; (b) medium $(F>Y>G)$; and (c) small $(Y \leq G)$ according to (Ibraimov \& Mirrakhimov, 1985).

The distribution of the numbers and mean number of Q-HR per individual in samples were compared using the Student $t$ - test.

\section{Results}

It should be emphasized that in comparative population cytogenetic studies only autosomal Q-HRs are considered. Nevertheless, variability of the largest Q-heterochromatin band in the human genome, localized on the q12 segment of the Y chromosome, has been mainly considered separately from the quantitative variability of autosomal Q-HRs (Geraedts \& Pearson, 1974; Müller et al., 1975; Buckton et al., 1976; Lubs et al., 1977; Yamada \& Hasegawa, 1978; Al-Nassar, 1981; Ibraimov \& Mirrakhimov, 1982 a, b, c; Ibraimov et al., 1982; $1986 ; 1990 ; 1991 ; 2000 ; 2013)$. Table 1 shows the distribution of the numbers and mean number of Q-HRs on autosomes in males and females in two age groups of Kazakh nationality. 
Table 1. Distribution of the numbers and mean number of Q-HRs on autosomes in males and females in newborns and $18-25$ years individuals of Kazakh nationality

\begin{tabular}{|c|c|c|c|c|}
\hline \multirow{3}{*}{ Number of Q-HRs } & Newborns & \multirow{2}{*}{$\begin{array}{c}\text { Newborns } \\
\text { Girls } \\
(\mathrm{n}=182)\end{array}$} & Males & Females \\
\hline & $\begin{array}{c}\text { Boys } \\
(\mathrm{n}=207)\end{array}$ & & $\begin{array}{c}18-25 \text { years } \\
(\mathrm{n}=49)\end{array}$ & $\begin{array}{c}18-25 \text { years } \\
(\mathrm{n}=190)\end{array}$ \\
\hline & I & II & III & IV \\
\hline 0 & 3 & 1 & & \\
\hline 1 & 5 & 4 & 9 & 7 \\
\hline 2 & 39 & 21 & 12 & 24 \\
\hline 3 & 47 & 38 & 13 & 45 \\
\hline 4 & 51 & 46 & 11 & 49 \\
\hline 5 & 37 & 39 & 4 & 40 \\
\hline 6 & 18 & 20 & & 17 \\
\hline 7 & 7 & 13 & & 7 \\
\hline Total & 770 & 750 & 136 & 745 \\
\hline Mean number & $3.72 \pm 0.102$ & $4.12 \pm 0.111$ & $2.78 \pm 0.176$ & $3.92 \pm 0.104$ \\
\hline Statistics & $\begin{array}{l}\mathrm{t}_{\mathrm{I}, \mathrm{II}}= \\
\mathrm{t}_{\mathrm{II}, \mathrm{III}}= \\
\mathrm{t}_{\mathrm{III}, \mathrm{IV}}= \\
\mathrm{t}_{\mathrm{I}, \mathrm{III}}= \\
\mathrm{t}_{\mathrm{II}, \mathrm{IV}}=\end{array}$ & $\begin{array}{l}.649 ; \\
5.775 ; \\
5.119 ; \\
.137 ; \\
1.313 ;\end{array}$ & $\begin{array}{l}\mathrm{P}=0 \\
\mathrm{P}=<0 \\
\mathrm{P}=<0 \\
\mathrm{P}=<0 \\
\mathrm{P}=0\end{array}$ & $\begin{array}{l}08^{*} \\
001 * \\
001 * \\
001 * \\
90\end{array}$ \\
\hline
\end{tabular}

* - these differences are statistically significant.

As can be seen from this Table, in every case females are characterized by the highest mean number value, and by a broad range of variability in the distribution of the numbers of chromosomal Q-HRs as compared to males. These differences are statistically significant. Such regularities as in Kazakhs was also found in Russian samples (data not shown).

And the question arises of why still comparative population cytogenetic studies did not show statistically significant differences in the number of autosomal Q-HRs between the sexes, where such attempts have been made (Geraedts \& Pearson, 1974; Müller et al., 1975; Kalz et al., 2005; Decsey et al., 2006). The answer to this question could perhaps be drawn from the data we have obtained in the previous study (Tables 2 and 3 ) (Ibraimov et al., 2013, 2014). 
Table 2. Distribution of the numbers and mean number of chromosomal Q-HRs per individual in Kazakh samples

\begin{tabular}{|c|c|c|c|}
\hline Number of Q-HRs & $\begin{array}{c}\text { Newborns } \\
(\mathrm{n}=389) \\
\mathrm{I}\end{array}$ & $\begin{array}{c}18-25 \text { years } \\
(\mathrm{n}=239) \\
\text { II }\end{array}$ & $\begin{array}{c}60 \text { years and older } \\
(\mathrm{n}=33) \\
\text { III }\end{array}$ \\
\hline 0 & $4(1.0 \%)$ & & $2(6.0 \%)$ \\
\hline 1 & $9(2.3 \%)$ & $16(6.7 \%)$ & $5(15.1 \%)$ \\
\hline 2 & $60(15.4 \%)$ & $36(15.1 \%)$ & $7(21.2 \%)$ \\
\hline 3 & $85(21.9 \%)$ & $58(24.3 \%)$ & $12(36.4 \%)$ \\
\hline 4 & $97(24.9 \%)$ & $60(25.1 \%)$ & $6(18.2 \%)$ \\
\hline 5 & $76(19.5 \%)$ & $44(18.4 \%)$ & $1(3.0 \%)$ \\
\hline 6 & $38(9.8 \%)$ & $17(7.1 \%)$ & \\
\hline 7 & $20(5.1 \%)$ & $7(2.9 \%)$ & \\
\hline 8 & & $1(0.4 \%)$ & \\
\hline Total & $1520(99.9 \%)$ & $881(100.0 \%)$ & $84(99.9 \%)$ \\
\hline $\begin{array}{c}\text { Mean number of } \\
\text { Q-HRs }\end{array}$ & $3.91 \pm 0.07$ & $3.69 \pm 0.09$ & $2.55 \pm 0.213$ \\
\hline Statistics & $\begin{aligned} \mathrm{t}_{\mathrm{I}, \mathrm{II}} & =1.808 ; \\
\mathrm{t}_{\mathrm{I}, \mathrm{III}} & =5.068 ; \\
\mathrm{t}_{\mathrm{II}, \mathrm{III}} & =4.259 ;\end{aligned}$ & $\begin{array}{l}\mathrm{df}=626 \\
\mathrm{df}=420 \\
\mathrm{df}=270\end{array}$ & $\begin{array}{l}\mathrm{P}=0.071 ; \\
\mathrm{P}=<0.001 ; * \\
\mathrm{P}=<0.001 ; *\end{array}$ \\
\hline
\end{tabular}

* - these differences are statistically significant.

Table 3. Distribution of the numbers and mean number of chromosomal Q-HRs per individual in Russian samples

\begin{tabular}{cccc}
\hline Number of Q-HRs & $\begin{array}{c}\text { Newborns } \\
(\mathrm{n}=83)\end{array}$ & $\begin{array}{c}18-25 \text { years } \\
(\mathrm{n}=60)\end{array}$ & $\begin{array}{c}60 \text { years and older } \\
(\mathrm{n}=80)\end{array}$ \\
\hline 0 & $1(1.2 \%)$ & $\mathrm{II}$ & $4(5.0 \%)$ \\
1 & $4(4.8 \%)$ & $4(6.6 \%)$ & $6(7.5 \%)$ \\
2 & $9(10.8 \%)$ & $7(11.7 \%)$ & $28(35.0 \%)$ \\
3 & $14(16.9 \%)$ & $14(23.3 \%)$ & $23(28.7 \%)$ \\
4 & $30(36.1 \%)$ & $17(28.3 \%)$ & $14(17.5 \%)$ \\
5 & $16(19.3 \%)$ & $13(21.6 \%)$ & $5(6.2 \%)$ \\
6 & $6(7.2 \%)$ & $4(6.6 \%)$ & \\
7 & $3(3.6 \%)$ & $1(1.6 \%)$ & \\
Total & $321(99.9 \%)$ & $224(99.9 \%)$ & $212(99.9 \%)$ \\
\hline Mean number of Q-HRs & $3.87 \pm 0.156$ & $3.73 \pm 0.177$ & $2.65 \pm 0.133$ \\
\hline \multirow{5}{*}{ Statistics } & $\mathrm{t}_{\mathrm{I}, \mathrm{II}}=0.502 ;$ & $\mathrm{df}=141 ;$ & $\mathrm{P}=0.575$ \\
& $\mathrm{t}_{\mathrm{I}, \mathrm{III}}=5.895 ;$ & $\mathrm{df}=161 ;$ & $\mathrm{P}=<0.001 *$ \\
& $\mathrm{t}_{\mathrm{II}, \mathrm{III}}=4.980 ;$ & $\mathrm{df}=138 ;$ & $\mathrm{P}=<0.001 *$ \\
\hline
\end{tabular}

* - these differences are statistically significant. 
So, judging by the data presented in Tables 2 and 3, there are no statistically significant differences between newborns and samples of young adults (18-25 year olds) that contradict existing observations (Ibraimov et al., $1986,1990,1991,2000)$. It was found that the main reasons for the lack of differences between the two age groups were: a) the combination of individuals of both sexes in the same group, and b) the predominance of girls

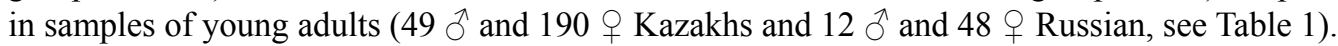

It has long been noted that at the population level, due to the largest block of Q-heterochromatin on Y chromosome in males, amount of Q-HRs on autosomes is less than in females (Ibraimov et al., 1986, 2000). This fact prompted us return to the problem of sex differences in the number of chromosomal Q-HRs at the level of human populations to get an answer to the question: why the number of Q-HRs on autosomes in female individuals more than in males?

First we show the results of all our previous observations on the populations of Eurasia and Africa, which, in general, indicate that there is some connection between the mean number of Q-HRs and sizes of Q-heterochromatin bands on Y chromosome (Table 4).

Table 4. Frequency of the Y chromosome of various sizes and mean number of autosomal Q-HRS in certain populations of Eurasia and Africa

\begin{tabular}{|c|c|c|c|c|c|}
\hline Populations & $\mathrm{n}$ & $\mathrm{m}$ & $\begin{array}{l}\mathrm{Y} \geq \mathrm{F} \\
\text { Large }\end{array}$ & $\begin{array}{l}\mathrm{F}>\mathrm{Y}>\mathrm{G} \\
\text { Medium }\end{array}$ & $\begin{array}{l}\mathrm{Y} \leq \mathrm{G} \\
\text { Small }\end{array}$ \\
\hline Mozambique Negroes & 148 & 4.72 & $\begin{array}{c}20(13.5 \%) \\
\mathrm{m}=4.40\end{array}$ & $\begin{array}{c}109(73.6 \%) \\
\mathrm{m}=4.69\end{array}$ & $\begin{array}{c}19(12.8 \%) \\
\mathrm{m}=5.26\end{array}$ \\
\hline Zimbabwe Negroes & 34 & 4.65 & $\begin{array}{l}4(11.8 \%) \\
m=2.75\end{array}$ & $\begin{array}{c}27(79.4 \%) \\
\mathrm{m}=4.93\end{array}$ & $\begin{array}{l}3(8.8 \%) \\
\mathrm{m}=4.67\end{array}$ \\
\hline Angola Negroes & 132 & 4.64 & $\begin{array}{l}6(4.5 \%) \\
m=4.00\end{array}$ & $\begin{array}{c}111(84.1 \%) \\
\mathrm{m}=4.61\end{array}$ & $\begin{array}{c}15(11.4 \%) \\
\mathrm{m}=5.21\end{array}$ \\
\hline Northern India Indians & 41 & 3.11 & $\begin{array}{c}12(29.3 \%) \\
\mathrm{m}=1.91\end{array}$ & $\begin{array}{c}29(70.7 \%) \\
\mathrm{m}=4.31\end{array}$ & $0(0.0 \%)$ \\
\hline Ethiopians & 17 & 3.06 & $\begin{array}{c}4(23.5 \%) \\
m=2.00\end{array}$ & $\begin{array}{c}13(76.5 \%) \\
m=3.40\end{array}$ & $0(0.0) \%)$ \\
\hline Southern Kazakhstan Kazakhs & 119 & 2.95 & $\begin{array}{c}16(13.4 \%) \\
\mathrm{m}=2.31\end{array}$ & $\begin{array}{c}84(70.6 \%) \\
m=3.02\end{array}$ & $\begin{array}{c}19(16.0 \%) \\
\mathrm{m}=3.21\end{array}$ \\
\hline Southern Siberia Khakass & 49 & 2.43 & $\begin{array}{c}11(22,4 \%) \\
m=2,18\end{array}$ & $\begin{array}{c}29(59,2 \%) \\
m=2,28\end{array}$ & $\begin{array}{c}9(18,4 \%) \\
m=3,22\end{array}$ \\
\hline Western Siberia Nenets & 60 & 2.30 & $\begin{array}{c}9(15,0 \%) \\
\mathrm{m}=1,30\end{array}$ & $\begin{array}{c}47(78.3 \%) \\
\mathrm{m}=2,40\end{array}$ & $\begin{array}{l}4(6,7 \%) \\
m=2,50\end{array}$ \\
\hline Far North Chukchi & 55 & 2.09 & $\begin{array}{c}20(36.4 \%) \\
\mathrm{m}=1.30\end{array}$ & $\begin{array}{c}32(58.2 \%) \\
\mathrm{m}=2.59\end{array}$ & $\begin{array}{l}3(5.5 \%) \\
\mathrm{m}=2.00\end{array}$ \\
\hline Russians & 360 & 2.09 & $\begin{array}{c}56(15.6 \%) \\
\mathrm{m}=1.53\end{array}$ & $\begin{array}{c}280(77.8 \%) \\
\mathrm{m}=2.18\end{array}$ & $\begin{array}{c}24(6.6 \%) \\
m=2.58\end{array}$ \\
\hline Chinese & 27 & 2.07 & $\begin{array}{c}8(29.6 \%) \\
m=1.38\end{array}$ & $\begin{array}{c}19(70.4 \%) \\
m=2.37\end{array}$ & $0(0.00 \%)$ \\
\hline Kyrgyz of Pamir and Tien-Shan & 152 & 1.91 & $\begin{array}{c}16(10.5 \%) \\
\mathrm{m}=1.43\end{array}$ & $\begin{array}{c}125(82.2 \%) \\
\mathrm{m}=2.13\end{array}$ & $\begin{array}{l}11(7.3 \%) \\
\mathrm{m}=2.18\end{array}$ \\
\hline Western Siberia Yakuts & 46 & 1.69 & $\begin{array}{l}1(2 / 2 \%) \\
m=1.00\end{array}$ & $\begin{array}{c}42(91.3 \%) \\
m=1.71\end{array}$ & $\begin{array}{l}3(6.5 \%) \\
m=1.67\end{array}$ \\
\hline Western Siberia Selkups & 66 & 1.56 & $\begin{array}{c}13(19.7 \%) \\
\mathrm{m}=1.77\end{array}$ & $\begin{array}{c}48(72.7 \%) \\
m=1.52\end{array}$ & $\begin{array}{l}5(7.6 \%) \\
m=1.40\end{array}$ \\
\hline Western Siberia Khanty & 22 & 1.50 & $\begin{array}{l}2(9.1 \%) \\
\mathrm{m}=1.00\end{array}$ & $\begin{array}{c}17(77.3 \%) \\
\mathrm{m}=1.50\end{array}$ & $\begin{array}{c}3(13.6 \%) \\
\mathrm{m}=1.30\end{array}$ \\
\hline
\end{tabular}

$\mathrm{n}$ - sample size; $\mathrm{m}$ - mean number of Q-HRs per individual in the population. 
These data gave us reason to believe that: 1) Q-heterochromatin on the Y chromosome, being the largest in the human genome, somehow "restricts" the total content of Q- HR on the autosomes in males and 2) Q-HRs on human chromosomes appears to have a common nature, regardless of the characteristics of their localization in the karyotype. The legitimacy of such an assumption is confirmed by our new data.

Thus, Table 5 presents the distribution of the numbers and mean number of autosomal Q-HRs in males with Y chromosomes of various sizes in Kazakh newborns. If until now the existence of a close connection between the number of Q-HRs on autosomes and the size of Q-heterochromatin on the $\mathrm{Y}$ chromosome at the population level were showed by only adult individuals (Table 4), this time we found the same pattern in newborns. The same patterns were found in Russian samples (data not shown).

Table 5. Distribution of the numbers and mean number of autosomal Q-HRs in males with Y chromosomes of various sizes in Kazakh newborns

\begin{tabular}{|c|c|c|c|}
\hline \multirow{4}{*}{ Number of Q-HRs } & Large & Medium & Small \\
\hline & $\mathrm{Y} \geq \mathrm{F}$ & $\mathrm{F}>\mathrm{Y}>\mathrm{G}$ & $\mathrm{Y} \leq \mathrm{G}$ \\
\hline & $(\mathrm{n}=53)$ & $(\mathrm{n}=102)$ & $(\mathrm{n}=32)$ \\
\hline & I & II & III \\
\hline 0 & 3 & & \\
\hline 1 & 5 & 1 & \\
\hline 2 & 21 & 12 & 2 \\
\hline 3 & 11 & 26 & 1 \\
\hline 4 & 6 & 28 & 10 \\
\hline 5 & 7 & 22 & 13 \\
\hline 6 & & 10 & 4 \\
\hline 7 & & 3 & 2 \\
\hline Total & 139 & 406 & 150 \\
\hline Mean number of Q-HRs & $2.62 \pm 0.185$ & $3.98 \pm 0.129$ & $4.69 \pm 0.203$ \\
\hline & $\mathrm{t} \mathrm{I}, \mathrm{II}=6.077$ & $\mathrm{df}=153$ & $\mathrm{P}=<0.001 *$ \\
\hline Statistics & t II, III = 2.748; & $\mathrm{df}=132$ & $\mathrm{P}=0.007 *$ \\
\hline & $\mathrm{t} \mathrm{I}, \mathrm{III}=7.223$ & $\mathrm{df}=83$ & $\mathrm{P}=<0.001 *$ \\
\hline
\end{tabular}

* - these differences are statistically significant.

The amount of chromosomal Q-HRs in the human genome can be additionally evaluated according to their size and intensity of fluorescence on a five-point degree (Paris Conference, 1971, 1975). Later, recommendations of the Paris Conference on this issue have been further developed in a number of papers (Muller et al., 1975; Buckton et al., 1976; Lubs et al., 1976; Yamada \& Hasegawa, 1978) and comparative population studies began to consider Q-bands with only 4 and 5 degrees of fluorescence intensity. In estimating the size of Q-HRs we adhered to the recommendations of Yamada and Hasegawa (1978) according to which the sizes of Q-bands were divided into five degrees, comparing them with the short arm of chromosome 18. However, mostly Q-HRs of medium $(>0,5-0,75 \times 18 \mathrm{p})$ and large $(>0,75-1,0 \times 18 \mathrm{p})$ sizes are found in a population. Abbreviation "QFQ" stands for "Q-bands by fluorescence using quinacrine" (Paris Conference, 1970, 1975). For example, "QFQ 15" indicates that the given Q-band has the medium size with very bright fluorescence. For clarity, Figure 1 shows an example of a karyotype with 3 chromosomal Q-HRs. 


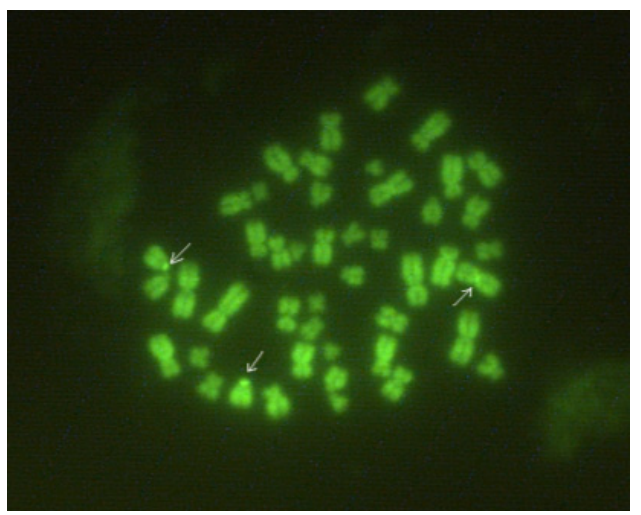

Figure 1. Q-HRs of large sizes and 5th degree intensity of fluorescence on the short arms of both chromosomes 13 and Q-HR of medium size and 5th degree of fluorescence intensity in the pericentric region of chromosome 3

Table 6 presents data on the size and intensity of fluorescence of chromosomal Q-HRs in newborns and young adults (18-25 year-olds) of the Kazakh nationality. In the examined samples of individuals QFQ points ranged from 15 to 112 . Here QFQ 15 indicates that the genome of a given individual has one Q-HR of medium size with the intensity of fluorescence equal to 5 degrees. While, QFQ 98 means that the karyotype of this individual has seven Q-HRs of medium size with the fluorescence intensity of 5 degrees. For statistical analysis types of Q-HRs we divided into 7 groups: Group 1 (14, 15 points); Group 2 (28, 29 points), Group 3 (40 to 45 points); Group 4 (53 to 58 points); Group 5 (from 67 to 73 points), Group 6 (80 to 86 points); Group 7 (98 to 112 points). In other words, Group 1 included individuals the karyotype of which had only one Q-HR, Group 2 with two, and the remaining groups with three or more Q-bands with intensity of fluorescence of 5 degrees.

Table 6. Types of Q-HRs on autosomes in males and females in newborns and 18 - 25 years individuals of Kazakh nationality

\begin{tabular}{|c|c|c|c|c|}
\hline Types of Q-HRs & $\begin{array}{c}\text { Newborns } \\
\text { Boys } \\
(\mathrm{n}=180)\end{array}$ & $\begin{array}{c}\text { Newborns } \\
\text { Girls } \\
(\mathrm{n}=159)\end{array}$ & $\begin{array}{c}\text { Males } \\
\text { 18- } 25 \text { years } \\
(\mathrm{n}=43) \\
\end{array}$ & $\begin{array}{c}\text { Females } \\
18-25 \text { years } \\
(\mathrm{n}=120) \\
\end{array}$ \\
\hline & I & II & III & \\
\hline 0 & 3 & 2 & & \\
\hline 1 & 6 & 4 & 8 & 7 \\
\hline 2 & 34 & 15 & 7 & 14 \\
\hline 3 & 40 & 33 & 13 & 28 \\
\hline 4 & 42 & 36 & 12 & 30 \\
\hline 5 & 36 & 40 & 2 & 26 \\
\hline 6 & 14 & 14 & 1 & 11 \\
\hline 7 & 5 & 13 & & 4 \\
\hline 8 & & 4 & & \\
\hline Total & 661 & 668 & 125 & 463 \\
\hline Mean number & $3.67 \pm 0.110$ & $4.20 \pm 0.668$ & $2.91 \pm 0.193$ & $3.83 \pm 0.132$ \\
\hline Statistics & $\begin{array}{l}\text { t I, II = 3.164; } \\
\text { t III, IV = 3.807; }\end{array}$ & $\begin{array}{l}\mathrm{df}=337 \\
\mathrm{df}=161\end{array}$ & $\begin{array}{l}\mathrm{P}=0 . \\
\mathrm{P}=<\end{array}$ & $\begin{array}{l}02 * \\
.001 *\end{array}$ \\
\hline
\end{tabular}

* - these differences are statistically significant. 
As shown in this Table, in the genome of females the amount of chromosomal Q-HRs significant more not only in number but also in size and intensity of fluorescence. Similar data were obtained in Russian samples (data not shown).

The literature shows the absence of statistically significant differences between the sexes in frequencies of chromosomal Q-HRs in Q-polymorphic loci of seven autosomes (Geraedts \& Pearson, 1974; Buckton et al., 1976; Lin et al., 1976; Schwinger, 1976; Yamada \& Hasegawa, 1978). However, the quantitative variability of chromosomal Q-HRs can be assessed, in addition to their frequency on seven Q-polymorphic autosomes, through their mean numbers, size and intensity of fluorescence (Paris Conference, 1971, 1975). Unfortunately, not all authors provide primary quantitative data indicating the number, size and intensity of fluorescence of chromosomal Q-HRs, to allow additional comparative statistical analysis.

It is generally known that the size of the Q-heterochromatin on the long arm of a Y chromosome of even medium size is greater than that of the Q-HRs on any of seven Q-polymorphic autosomes in the human karyotype, especially as the morphological variability of the $\mathrm{Y}$ chromosome (large, medium, small) is mainly determined by the size of the Q-heterochromatin segment on its long arm. Based on the data presented above, we assume, that the Q-heterochromatin band on the Y chromosome, being the largest Q-heterochromatin segment in the human genome, somehow 'restricts' the overall number of Q-HRs on autosomes in males. Apparently, for the same reason, amount of autosomal Q-HRs increases in females compared to males within each individual population (Ibraimov, 1983b). In addition, human chromosomal Q-HRs may have a basically similar role regardless of their location in the karyotype (Ibraimov, 2010).

\section{Discussion}

Why the detection of the existence of significant differences between the sexes in the number of Q-HRs on autosomes is not so simple? We believe that this is due to following facts: 1) so far all authors compared males and females only on frequencies of Q-HRs in twenty Q-polymorphic loci of seven autosomes, leaving aside such important quantitative characteristics as the distribution of the numbers, size and intensity of fluorescence of chromosomal Q-HRs in population; 2) it is taken for granted that in total there is on average twice more Q-HRs in the genome of males than of females, for the reason that there is $\mathrm{Y}$ chromosome in karyotype of males, which contains the largest block of Q- heterochromatin in human genome; 3) compared samples of male and female individuals were of different age groups; 4) extremely wide variability of sizes of Q-heterochromatin on Y chromosomes in human populations were not taken into account. In other words, the possible existence of a close connection between the quantitative content of Q-HRs on autosomes and the size of Q- heterochromatin of the Y chromosome at the population level were not expected. Specifically, no one tried to assess the possible impact of a large Q-heterochromatin material of the Y chromosome on the amount of Q-HRs on autosomes in the human genome.

So far it seems correct to us to explain the increasing number of chromosomal Q-HRs on autosomes in females at the population level by the existence of some evolutionary established mechanism that "compensates" the difference in the "dose" of Q-heterochromatin material in the female genome due to the lack of chromosomes in their karyotype, which carries largest Q-HR, as Y chromosome (Ibraimov, 1983b, 2010). Apparently, there is some mechanism that limits the "dose" of chromosomal Q-HRs in the human genome to a certain level. Indeed, the human karyotype has 25 loci ( 3 cen, 4 cen, 13 p11, 13 p13, 14 p11, 14 p13, 15 p11, 15 p13, 21 p11, 21 p13, $22 \mathrm{p} 11,22$, p13 and Yq12), where Q-heterochromatin can potentially be detected. However, as yet no one could found 25 chromosomal Q-HRs in the human karyotype; usually their number varies from 0 to 10 (Yamada \& Hasegawa, 1978; Al-Nassar et al., 1981; Ibraimov \& Mirrakhimov, 1985; Ibraimov, 2010).

The existence of significant sex differences at the population level raises the question of the revision of the published literature data on the mean number of Q-HRs per individual in population. Let's just take one example from our own experience. Earlier, after examining the children aged 13-16 years we reported that the mean number for the Kazakhs of Kazakhstan is $3.56 \pm 0.168$ (Ibraimov et al., 1982). We obtained similar data 30 years later, examining the students of the Kazakh nationality in Almaty (Ibraimov et al., 2013). Now, after studying the amount of chromosomal Q-HRs in newborns and elderly Kazakhs, we realized that our conclusion does not correspond to the reality (see Table 2). Therefore, while presenting and discussing the data on the amount of chromosomal Q-HRs in the genome of a given population we should show the mean number values separately for male and female samples with the mandatory indication of their age.

In conclusion, as expected, in general, the total amount of chromosomal Q-HRs in the male genome is greater than that of female. Indeed, the size of Q-HRs of Y chromosome of even medium size is so large that it is equal to two-three average autosomal Q-HRs in human karyotype. However, this does not mean that the total amount 
of chromosomal Q-HRs in the males' genome at the population level on average is twice greater than of females (Paris Conference, 1971, 1975). Our previous observations (Ibraimov, 1983b; Ibraimov et al., 1986, 1990, 1991, $2000,2014)$ as well as the results of this study show that, apparently, there is some mechanism that compensates for the deficiency of Q-heterochromatin material in the female genome due to the lack of Y chromosome in their karyotype by increasing the amount of Q-HRs on autosomes. This pattern persists regardless of age and racial-ethnic characteristics of human populations. Therefore, a preponderance of the total amount of Q-HRs in the genome of the male on the level of human populations still persists.

\section{Acknowledgements}

We wish to express our gratitude to the students of Kazakh National Medical University and the elderly people from the Old People's Home of Almaty city for their cooperation.

\section{References}

Al-Nassar, K. E., Palmer, C. G., Connealy, P. M., \& Pao-Lo, Yu. (1981). The genetic structure of the Kuwaiti population. II. The distribution of Q-band chromosomal heteromorphisms. Hum. Genet., 57, 423-427. http://dx.doi.org/10.1007/BF00282021

Buckton, K. E., O’Riordan, M. L., Jacobs, P. A., Robinson, J. A., Hill, R., \& Evans, H. J. (1976). C- and Q-band polymorphisms in the chromosomes of three human populations. Ann. Hum. Genet., 40, 90-112. http://dx.doi.org/10.1111/j.1469-1809.1976.tb00168.x

Decsey, K., Bellovits, O., \& Bujdoso, G. M. (2006). Human chromosomal polymorphism in a Hungarian sample. Int. J. Hum. Genet., 6(3), 177-183.

Geraedts, J. P. M., \& Pearson, P. L. (1974). Fluorescent chromosome polymorphisms: frequencies and segregation in a Dutch population. Clin. Genet., 6, 247-257. http://dx.doi.org/10.1111/j.1399-0004.1974.tb02086.x

Hungerford, D. A. (1965). Leucocytes cultured from small inocula of whole blood and preparation of metaphase chromosomes by treatment with hypotonic KCl. Stain Technol., 40, 333-338.

Ibraimov, A. I. (1983a). Chromosome preparations of human whole lymphocytes - an improved technique. Clin. Genet., 24, 240-242. http://dx.doi.org/10.1111/j.1399-0004.1983.tb00077.x

Ibraimov, A. I. (1983b). Human chromosomal polymorphism. VII. The distribution of chromosomal Q-polymorphic bands in different human populations. Hum. Genet., 63, 384-391. http://dx.doi.org/10.1007/BF00274767

Ibraimov, A. I. (2010). Chromosomal Q-heterochromatin regions in populations and human adaptation. In M. K. Bhasin \& C. Susanne (Eds.), Anthropology Today: Trends and Scope of Human Biology (pp. 225-250). Delhi: Kamla- Raj Enterprises.

Ibraimov, A. I., Akanov, A. A., Meymanaliev, T. S., Karakushukova, A. S., Kudrina, N. O., Sharipov, K. O., \& Smailova, R. D. (2013). Chromosomal Q-heterochromatin polymorphisms in 3 ethnic groups (Kazakhs, Russians and Uygurs) of Kazakhstan. Int. J. Genet., 5(1), 121-124.

Ibraimov, A. I., Akanov, A. A., Meymanaliev, T. S., Smailova, R. D., \& Baigazieva, G. D. (2014). Chromosomal Q-heterochromatin and age in human population. $J M B R$ (in press).

Ibraimov, A. I., Axenrod, E. I., Kurmanova, G. U., \& Turapov, O. A. (1991). Chromosomal Q-heterochromatin regions in the indigenous population of the northern part of West Siberia and new migrants. Cytobios., 67, 95-100.

Ibraimov, A. I., Karagulova, G. O., \& Kim, E. Y. (2000). The relationship between the Y chromosome size and the amount of autosomal Q-heterochromatin in human populations. Cytobios., 102, 35-53.

Ibraimov, A. I., Kurmanova, G. U., Ginsburg, E. Kh., Aksenovich, T. I., \& Axenrod, E. I. (1990). Chromosomal Q-heterochromatin regions in native highlanders of Pamir and Tien-Shan and in newcomers. Cytobios., 63, 71-82.

Ibraimov, A. I., \& Mirrakhimov, M. M. (1982a). Human chromosomal polymorphism. III. Chromosomal Q-polymorphism in Mongoloids of northern Asia. Hum. Genet., 62, 252-257. http://dx.doi.org/10.1007/BF00333531 
Ibraimov, A. I., \& Mirrakhimov, M. M. (1982b). Human chromosomal polymorphism. IV. Chromosomal Q-polymorphism in Russians living in Kyrghyzia. Hum. Genet., 62, 258-260. http://dx.doi.org/10.1007/BF00333532

Ibraimov, A. I., \& Mirrakhimov, M. M. (1982c). Human chromosomal polymorphism. V. Chromosomal Q-polymorphism in African populations. Hum. Genet., 62,261-265. http://dx.doi.org/10.1007/BF00333533

Ibraimov, A. I., \& Mirrakhimov, M. M. (1985). Q-band polymorphism in the autosomes and the Y chromosome in human populations. In A. A. Sandberg \& R. Alan (Eds.), Progress and Topics in Cytogenetics. The Y chromosome. Part A. Basic Characteristics of the Y chromosome (pp. 213-87). New York: Liss Inc.

Ibraimov, A. I., Mirrakhimov M. M., Axenrod E. I., \& Kurmanova, G. U. (1986). Human chromosomal polymorphism. IX. Further data on the possible selective value of chromosomal Q-heterochromatin material. Hum. Genet., 73,151-156. http://dx.doi.org/10.1007/BF00291606

Ibraimov, A. I., Mirrakhimov, M. M., Nazarenko, S. A., Axenrod, E. I., \& Akbanova, G. A. (1982). Human chromosomal polymorphism. I. Chromosomal Q-polymorphism in Mongoloid populations of Central Asia. Hum. Genet., 60, 1-7. http://dx.doi.org/10.1007/BF00281254

John, B. (1988). The biology of heterochromatin. In R. S. Verma (Ed.), Heterochromatin: molecular and structural aspects (pp. 1-147). Cambridge University Press.

Kalz, L., Kalz-Fuller, B., Hedge, S., \& Schwanitz, G. (2005). Polymorphism of Q-band heterochromatin; qualitative and quantitative analyses of features in 3 ethnic groups (Europeans, Indians, and Turks). Int. J. Hum. Genet., 5(2), 153-163.

Lin, C. C., Gedeon, M. M., \& Griffith, M. M. (1976). Chromosome analysis on 930 consecutive newborn children using quinacrine fluorescent banding technique. Hum. Genet., 31, 315-328. http://dx.doi.org/10.1007/BF00270861

Lubs, H. A., Patil, S. R., Kimberling, W. J., Brown, J., Hecht, F., Gerald, P., \& Summitt, R. L. (1977). Racial differences in the frequency of Q- and C-chromosomal heteromorphism. Nature, 268, 631-632. http://dx.doi.org/10.1038/268631a0

Mckenzie, W. H., \& Lubs, H. A. (1975). Human Q and C chromosomal variations: distribution and incidence. Cytogenet. Cell Genet., 14, 97-115. http://dx.doi.org/10.1159/000130330

Müller, H. J., Klinger, H. P., \& Glasser, M. (1975). Chromosome polymorphism in a human newborn population. II. Potentials of polymorphic chromosome variants for characterizing the idiogram of an individual. Cytogenet. Cell Genet, 15, 239-255. http://dx.doi.org/10.1159/000130522

Paris Conference and Supplement. (1971, 1975). Standartization in human cytogenetics. Birth Defects, 6, 1-84.

Schwinger, E., \& Wehner, H. (1976). Frequency of chromosomal fluorescence polymorphism in normal persons and in clinical patients with diagnosed chromosome aberrations. Hum. Genet., 32, 115-119. http://dx.doi.org/10.1007/BF00291493

Stanyon, R., Studer, M., Dragone, A., De Benedictis, G., \& Brancati, C. (1988). Population cytogenetics of Albanians in Cosenza (Italy): frequency of Q- and C-band variants. Int. J. Anthropol., 3, 19-29.

Verma, R. S. (1988). Heteromorphisms of heterochromatin. In R. S. Verma (Ed.), Heterochromatin: molecular and structural aspects (pp. 1-147). Cambridge University Press.

Yamada, K., \& Hasegawa, T. (1978). Types and frequencies of Q-variant chromosomes in a Japanese population. Hum. Genet., 44, 89-98. http://dx.doi.org/10.1007/BF00283578

\section{Copyrights}

Copyright for this article is retained by the author(s), with first publication rights granted to the journal.

This is an open-access article distributed under the terms and conditions of the Creative Commons Attribution license (http://creativecommons.org/licenses/by/3.0/). 